\title{
Cuando las brujas vuelan y hacen daño. Esquemas culturales sobre la brujería del campesinado en Colombia
}

\section{When witches fly and cause damage. Cultural stereotypes about witchcraft among peasants in Colombia}

\author{
Alejandro Munévar Salazar ${ }^{*}$ \\ Laura Andrea Chaparro Rojas $* *$ \\ Julio Alexander Bernal Chávez ${ }^{\star * *}$ \\ doi.org/10.29043/liminar.v20i1.894
}

Resumen: Desde un enfoque dialectológico y etnográfico, en la presente investigación se describen y analizan algunos esquemas culturales del campesinado colombiano asociados a la brujería. Usando el Atlas lingüístico etnográfico de Colombia (1954-1983), este trabajo contrasta los materiales lingüísticos de los archivos sonoros con los mapas lingüísticos. Se adopta el concepto de "etnotextos" para profundizar en la lógica discursiva de las fuentes orales, y de los esquemas culturales a fin de dar cuenta de las experiencias y significados campesinos sobre la brujería en Colombia.

Palabras clave: esquemas culturales, etnotextos, campesinado, cultura popular, brujería.

Abstract: Using a dialectological and ethnographic approach, this study describes and analyzes a number of cultural stereotypes held by the Colombian peasantry regarding witchcraft. Based on the Atlas lingüístico etnográfico de Colombia (1954-1983), this paper contrasts the linguistic materials of sound archives and linguistic maps. It makes use of the concept of ethnotexts to delve into the discursive logic of oral sources on popular culture and cultural stereotypes to discuss various peasant experiences and meanings of witchcraft in Colombia.

Key words: cultural stereotypes, ethnotexts, peasantry, popular culture, witchcraft.

Recibido: 18 de enero de 2021

Aceptación: 28 de junio de 2021

Publicación: 12 de noviembre de 2021
* Instituto Caro y Cuervo, Bogotá, Colombia alejandro.munevar@caroycuervo.gov.co

(iD) 0000-0001-8818-3910

** Instituto Caro y Cuervo, Bogotá, Colombia laura.chaparro01@est.uexternado.edu.co (iD) 0000-0003-2559-8574

*** Instituto Caro y Cuervo, Bogotá, Colombia julio.bernal@caroycuervo.gov.co (iD) 0000-0002-1652-0145 


\section{Introducción}

$\mathrm{E}$ 1 Atlas Lingüístico Etnográfico de Colombia (1954-1983) (ALEC) (Flórez, 1983) comprende 17000 fotografías, 760 sesiones de audio, 1500 mapas lingüísticos y más de 1000 objetos etnográficos acerca de las 264 localidades a las cuales se dio prioridad para su investigación porque tenían tradiciones orales y usos de la lengua ya establecidos (Montes, 1976). Gracias a los contenidos lingüísticos y antropológicos recolectados, el ALEC se presenta como una fuente de información para comprender las formas de pensamiento campesinas en Colombia entre los años cincuenta y setenta del siglo pasado.

A continuación se abordan ciertas historias sobre brujas que el ALEC caracterizó como "muestras folclóricas" por ser representativas de las expresiones del campesinado en Colombia (Montes, 1976, p. 188). Los relatos populares de este tipo se analizan desde la propuesta de los "etnotextos", que sirvió a los dialectólogos de Le Nouvel Atlas Linguistique de la France par Régions (NALF) (1940-1980) (Dauzat, 1942), para entender los discursos de determinadas tradiciones populares en una dimensión tanto regional como nacional de la lengua en uso (Bouvier, 1978; Bouvier y Ravier, 1976; Joutard, 1981; Pelen, 1992, 2011).

La propuesta interdisciplinaria de los etnotextos permite interpretar las fuentes orales del corpus lingüístico del ALEC para buscar significados o conceptualizaciones colectivas. Dichos significados son estudiados en este caso desde la perspectiva teórica de los "esquemas culturales" (Malcolm y Sharifian, 2002), que son los sistemas lingüísticos relacionales que permiten a las personas, los grupos sociales y las culturas dar sentido a su entorno. El objetivo de la presente investigación es identificar algunas de las características del esquema cultural de la brujería del campesinado colombiano con el fin de comprender las interpretaciones del mundo natural que lo rodea.

Haciendo uso de las herramientas de la lingüística de corpus (Bernal e Hincapié, 2018) y la lingüística cultural (Malcolm y Sharifian, 2002), se analizan las maneras en que el campesinado ordena su vida cotidiana y su mundo alrededor de la brujería. La pregunta de investigación que nos planteamos es: ¿cuáles son los esquemas culturales del campesinado colombiano asociados a la brujería que les permiten nombrar y dar sentido a sus acciones y a su mundo?

En el marco más general de los estudios del campesinado, esta investigación busca entender la manera en que el campesinado de ciertas regiones de Colombia le da sentido a su entorno a partir de sus discursos. Basándonos en un estudio del léxico atribuido a las brujas en Colombia, se identifica un esquema cultural, el de las "brujas voladoras", y se observa en forma detallada cómo este esquema explica algunos de los motivos por los cuales los campesinos realizan determinadas acciones para espantar a las brujas, como evitar que estas les "hagan daño".

\section{Los etnotextos en la investigación del ALEC}

Los planteamientos teóricos del ALEC estuvieron influenciados por el método del dialectólogo suizo Jules Gilliéron, y especialmente por la escuela dialectológica Wörter und Sachen (palabras y cosas) (Flórez, 1964). A finales del siglo XIX y comienzos del XX, esta escuela se orientó a establecer relaciones entre los usos de la lengua y la cultura material para comprender el significado y la evolución de las palabras (Asatrian, 2009; Bernales, 1980). De esta propuesta proviene el vínculo entre los estudios dialectológicos 
y los etnográficos para entender las variaciones de la lengua hablada y su relación con los objetos físicos $\mathrm{o}$ abstractos a los que hace referencia.

Los casos del Nouvel Atlas Linguistique de la France par Régions (NALF) y el de los Atlas Linguistiques et Ethnographiques Régionaux de la France (1940-1980) muestran esta misma interpretación geográfica y etnográfica dentro de los estudios dialectológicos. En este sentido, los investigadores de estos corpus dialectales franceses se manifestaron de una manera más frecuente que los del ALEC al respecto de su metodología (Bouvier, 1978; Bouvier y Ravier, 1976; Joutard, 1981; Pelen, 1992).

Sobre la investigación del NALF, resalta el interés que presta a la evidencia dialectológica que favoreció la convergencia entre los campos de la geografía, la etnología francesa y la historia (Bouvier, 1978; Joutard, 1981). De este trabajo interdisciplinario, a finales de los años de 1970 se originó el término de "etnotextos", que se prefirió sobre otras nociones similares como "tradición oral", "cultura oral" o "textos orales". Estos refieren a la investigación de la cultura oral y la historia de un grupo social en particular (Joutard, 1981, p. 47).

En Francia, la posibilidad de investigar la oralidad mediante la noción de "etnotextos" consiguió que se profundizara en la lógica discursiva de las fuentes orales y se indagara en los conjuntos referenciales comunes que daban forma a determinadas identidades culturales o regionales. Con esta noción, la historiografía pudo definir de una mejor manera la cultura popular y afrontar el problema del funcionamiento de la memoria colectiva. La dialectología logró así vincular su trabajo de cartografía con la dimensión etnográfica de los discursos orales, mientras que la etnología francesa consiguió diferenciar los fenómenos etnolingüísticos de determinadas áreas culturales (Pelen, 1992, 2011).

Luego de un acercamiento teórico y metodológico a los atlas lingüísticos franceses y al atlas lingüístico colombiano (Munévar y Bernal, en prensa), se puede confirmar que el proyecto de investigación sobre los etnotextos es afín con los planteamientos que estructuraron el Atlas Lingüístico Etnográfico de Colombia (1954-1983). No obstante, vale la pena aclarar que el ALEC no es un atlas regional sino nacional, ya que su propósito principal fue construir un marco de desarrollo nacional para proyectos regionales posteriores: "El principal objeto del Atlas colombiano es dar [...] una idea preliminar de la distribución geográfica nacional de varios fenómenos importantes, trazar un esquema previo dentro del cual se puedan hacer más tarde investigaciones regionales intensas y particularizadas" (Flórez, 1964, p. 203).

El ALEC buscó llevar a cabo una visión general de la variedad dialectal de Colombia porque los estudios previos eran escasos y superficiales (Montes, 1976). Sus aspectos metodológicos muestran la insuficiencia de antecedentes sobre las regiones lingüísticas de Colombia y la razón de la división del proyecto en dos etapas: "una de realización de una serie de monografías completas de lugares distribuidos en las distintas zonas etnolingüísticas [...] y otra posterior en que, con base en los datos de estas monografías se confeccionaría el proyecto del atlas" (Montes, 1976, p. 190).

En la presente investigación se adopta la noción de "etnotextos", que permite la investigación e interpretación actual de los archivos orales del ALEC desde una perspectiva interdisciplinaria, en primer lugar porque se ha encontrado que su desarrollo teórico y metodológico se origina en los mismos planteamientos de la dialectología del siglo XX, y en segundo lugar porque, sea desde una perspectiva regional o nacional, sirve para buscar un mayor entendimiento de las particularidades de la vida campesina y popular colombiana a partir del estudio de la oralidad y de la memoria colectiva. Sin embargo, la adopción del concepto de etnotexto es una estrategia teórica para abordar las fuentes primarias y su análisis debe, por lo tanto, realizarse desde otras perspectivas teóricas complementarias. En nuestro caso, 
se trata de la propuesta de la lingüística cultural como disciplina y de una de sus herramientas analíticas representativas: el esquema cultural.

\section{La búsqueda de esquemas culturales en el corpus lingüístico}

El área multidisciplinaria de la lingüística cultural se centra en las relaciones entre el lenguaje y la cultura. Se desarrolla como una apuesta por integrar la lingüística cognitiva, la lingüística antropológica y la antropología cognitiva para comprender lo que se ha dado por llamar la cognición cultural (cultural cognition) (Sharifian, 2017). Es decir, la lingüística cultural se ocupa de estudiar el sistema relacional que forma la estructura cognitiva que está en la base del comportamiento social o colectivo (Nishida, 2005).

Para la lingüística cultural, los esquemas culturales son una herramienta analítica que sirve para identificar indicios anclados en el uso del lenguaje que explican cómo las personas, los grupos sociales y las culturas le dan sentido al mundo. En términos de Farzad Sharifian, se trata de "conceptualizaciones" que se codifican y comunican mediante el lenguaje: "La lingüística cultural explora, en términos explícitos, conceptualizaciones cuya base sea cultural, codificadas en y comunicadas a través del lenguaje humano" (Sharifian, 2017, p. 34, traducción propia). Por ello, su análisis se centra en el acto comunicativo del lenguaje para capturar aquellos patrones relacionales que conforman lo que podría ser una forma de pensamiento colectivo.

A estos patrones que se forman a partir del análisis lingüístico y cognitivo se les ha dado en llamar de distintas maneras. Se les llama modelos mentales (mental models) (Van Dijk, 2000), schemata (Shahgahsemi, 2017) o conceptualizaciones culturales (cultural conceptualisations) (Sharifian, 2017). Desde estas denominaciones se han desarrollado distintas ramas de pensamiento como la teoría crítica, la teoría marxista, la teoría feminista, la teoría poscolonial y la teoría funcionalista de los esquemas culturales (Shahgahsemi, 2017).

La definición que interesa en esta investigación es aquella de acuerdo con la cual se conciben los esquemas culturales como una herramienta que hace posible capturar el sistema cognitivo cultural a partir del análisis del discurso. Según esta lectura, los esquemas culturales son estructuras conceptuales que permiten a las personas almacenar información perceptual y conceptual sobre su cultura e interpretar experiencias y expresiones culturales (Malcolm y Sharifian, 2002).

Ahora bien, para poder identificar dichos esquemas se deben identificar patrones y repeticiones en los etnotextos escogidos para el estudio. Es por esa razón que acudimos a la propuesta de la lingüística de corpus y de sus herramientas de análisis de la lengua en uso para identificar patrones lingüísticos. Se sistematizan y analizan los datos del corpus lingüístico mediante herramientas computacionales (Antconc) para dar cuenta de la lengua en uso (Bernal e Hincapié, 2018). Así, se establece una armonía con el procedimiento metodológico propuesto por Ian Malcolm y Frazar Sharifian desde la lingüística cultural, con el que se clasifican los etnotextos del archivo sonoro para identificar los esquemas culturales que pertenecen al mundo campesino colombiano.

Según la propuesta de Ian Malcolm y Farzad Sharifian, el hallazgo de los esquemas culturales se realiza mediante la identificación de patrones semánticos en los discursos que comunican información perceptual y conceptual de los hablantes. Estos se dividen en tres etapas: en la primera se detectan los elementos léxicos (lexical items) distintivos que comunican los esquemas culturales almacenados cognitivamente; 
en la segunda se describen las asociaciones recurrentes y las estrategias discursivas que manifiestan la importancia semántica de los elementos léxicos, y en la tercera se deducen los esquemas culturales a partir de determinadas formas discursivas o genres (Malcolm y Sharifian, 2002).

A continuación se presentan algunos de los resultados de investigación sobre el trabajo de los mapas lingüísticos del ALEC ${ }^{1}$ y del archivo sonoro de este corpus lingüístico. El primer objetivo fue vincular las referencias de los mapas lingüísticos "bruja, hechicera" y "embrujar", con los etnotextos encontrados sobre brujas o brujería, el segundo consistió en detectar el esquema cultural que se exponía en los etnotextos, y el tercer fue dar cuenta del contenido de este esquema y de su aporte a la comprensión sobre la vida campesina y el patrimonio cultural colombiano.

\section{Las brujas en los mapas del ALEC}

En la literatura antropológica e historiográfica se puede reconocer que tanto "el vuelo" como "la metamorfosis" de las brujas son imágenes estereotipadas sobre la brujería que están presentes en la memoria colectiva de diferentes pueblos y lugares del mundo (Evans-Pritchard, 1976; Favret-Saada, 1980; Ginzburg, 1991; Michelet, 2004). En estos estudios de distintas épocas y enfoques sus autores analizan las relaciones de dominación entre clases dominantes y subalternas, en las cuales la brujería adquiere formas de resistencia en prácticas y concepciones del mundo predominantemente rurales.

La investigación antropológica sobre la existencia de un pensamiento mágico es extensa y toma distintas formas. En el caso colombiano, los estudios sobre brujería tratan de su relación con la colonización y la resistencia de minorías étnicas (Castaño y Suárez, 1992; Taussig, 1993), con el conflicto armado y la salud mental (Uribe, 2003), con las concepciones del cuerpo y la enfermedad (Bolaño, 2019; Carvajal, 2011; Gutiérrez de Pineda, 1985; Ramos, 2017; Taussig, 1993) y con las representaciones de la tragedia y el destino (Suárez, 2009).

Sin embargo, lo que interesa analizar aquí son las particularidades de la vida cotidiana y las conceptualizaciones colectivas campesinas y populares a partir del estudio de la oralidad. Dado que el sujeto de estudio es el campesinado que participó en las investigaciones del ALEC, se busca ofrecer una interpretación sobre la manera en que los campesinos de ciertas regiones de Colombia le dan sentido a su entorno a partir de sus discursos, que en este caso están asociados a la brujería.

Partimos de la observación de los mapas lingüísticos de las palabras "bruja, hechicera" y "embrujar", para detectar los elementos léxicos (lexical items) distintivos relacionados con el tema. Estos elementos léxicos pueden organizarse bajo la forma de una lista de atributos de los esquemas culturales de la brujería en Colombia. Se hace una breve descripción de estos distintos atributos para luego profundizar en dos etnotextos del corpus oral del ALEC, que nos permitirán analizar en detalle el esquema cultural de las "brujas voladoras", que se origina a partir de las menciones repetitivas y generalizadas del "vuelo" y la "metamorfosis" de las brujas.

\footnotetext{
${ }^{1}$ Los mapas lingüísticos, al igual que el archivo sonoro del corpus lingüístico, son algunos de los materiales del ALEC que sirvieron para registrar y sistematizar el patrimonio lingüístico y etnográfico de Colombia.

${ }^{2}$ Que sea esta una invitación para que los lectores se remitan a los mapas "bruja, hechicera” y "embrujar" que se encuentran en la consulta por mapa del ALEC digital (Instituto Caro y Cuervo, s. f.).
} 
En la observación del mapa "bruja, hechicera" se encuentran los léxicos frecuentes de "bruja, hechicera" y "hechicera”; y los menos frecuentes "vieja” (Boyacá), "maga" (Santander), "gruñetas" (Tolima), "zángana” (Santander), "pantasma” o "patasola” (Cundinamarca), "paredera" (Bolívar), "cochina” (Antioquia), "esdrújula” (Boyacá), "mula” (Chocó), "curandera” (Valle del Cauca), "bruja tierrera” (Antioquia, Córdoba) o "bruja explotadora” (Magdalena). De esta lista extensa de atributos para describir a las brujas colombianas, resaltan los siguientes atributos en los cuales se reconocen tres de las características que componen el complejo esquema cultural de la bruja: 1) sus intenciones malignas, como cuando llaman a la bruja "malhechora" (Casanare, Boyacá, Bolívar), "malijicera" (Santander) y "malina" (Magdalena); 2) sus dones premonitorios como "pitonisa" (Santander, Boyacá, Caldas), "gitana" (Antioquia) o "adivina" (Boyacá, Cundinamarca, Caquetá, Nariño), y 3) su conocimiento de plantas como "yopera” (Tolima), "bruja yerbatera” (Norte de Santander, Antioquia, Boyacá) o “yerbatera” (Cundinamarca, Boyacá, Caldas, Valle del Cauca, Nariño, Sucre, Tolima).

A los atributos ya mencionados se deben incluir también las referencias frecuentes a dos habilidades: el vuelo y la metamorfosis. En cuanto al vuelo de las brujas, se encuentran los siguientes conjuntos léxicos en los mapas: "bruja volantona" (Antioquia, Córdoba, Cesar), "volantona” (Antioquia), "bruja voladora” (Antioquia, Santander, Norte de Santander, Tolima, Huila, Nariño), "voladora” (Boyacá, Tolima, Huila, Nariño), "bruja volaria" (Boyacá, Cesar), "bruja volandera" (Norte de Santander), "bruja volona" (Norte de Santander) y "bruja arbolaria" (Norte de Santander). En todas las regiones que se visitaron para la elaboración del ALEC se encuentra mención a esta habilidad de las brujas con ciertas variaciones dialectales.

En cuanto a la metamorfosis, se registran los siguientes conjuntos léxicos sobre "las formas que toma la bruja": "En las noches las brujas voladoras toman forma de ave" (Chocó, Bolívar, Atlántico, Magdalena, Cesar), "se transforman en gallina" (Cauca, Sucre, Bolívar, Magdalena, Cesar), en "chulo o gallinazo" (Tolima, Boyacá, Cundinamarca), en "pisco o pisca negros" (Cauca, Caquetá, Tolima, Santander, Cesar), en "pata” (Atlántico, Magdalena, Cesar), en "paloma” (Santander, Cesar) y en "lechuza" (Cundinamarca), entre otras menciones que no refieren exclusivamente a aves sino a otros animales domésticos o salvajes que tienen interacciones y significados diferentes según los etnotextos campesinos de las distintas regiones de Colombia.

Debido al grado de generalidad con el que aparecen los léxicos relacionados con el vuelo y la metamorfosis, se opta por profundizar en ellos mediante la investigación de los etnotextos del corpus sonoro del ALEC. Se piensa que estos dos rasgos pueden recoger la mayoría de las maneras de referirse a las brujas puesto que hay expresiones como "En las noches las brujas voladoras toman forma de ave" (Chocó, Bolívar, Atlántico, Magdalena, Cesar), que muestran que en varios casos el vuelo y la metamorfosis se encuentran asociados entre sí. A continuación se describen estas asociaciones recurrentes en dos etnotextos seleccionados y las estrategias discursivas de los campesinos que reflejan el esquema cultural sobre las brujas voladoras.

\section{Brujas voladoras: las brujas que suenan}

En Coredó, Chocó, en febrero de 1975, una madre viuda de 56 años de edad relata sus labores cotidianas sobre "trabajar el monte". Ella "chasquea" el monte o mantiene limpio el terreno para sembrar y desyerbar arroz, yuca, verdura y plátano, mientras sus hijos le ayudan en las tareas de "hoyar monte" o sembrar 
las semillas y cubrir con tierra los hoyos del cultivo. Aquilina Córdoba menciona que cotidianamente ahuyenta a un pájaro de los sembradíos: "haciéndole bulla, con latas y gritándole a aquel chamón, un pájaro negrito". Y cuando le preguntan sobre las brujas, ella cuenta que una vez tuvo que espantar otro pájaro diferente:

ENC: $\mathrm{Y}$ ¿las brujas?, cuente de las brujas.

INF: Bueno, las brujas, sí, eso por aquí muy poquito. Aquí no hay.

ENC: ¿Usted nunca las ha oído?

INF: No, yo sí. Aquí, yo las vi. Así, había una que bajaba de allá. Uno las siente en el aire que va volando con un ruido.

ENC: Y ¿cómo hace?

INF: Eh, "bum bum bum" [SS: Onomatopeya], Atentito. Y sí, se sienta aquí en el copete de esta casa. Siente uno la casa y entonces una noche los muchachitos me dijeron: "mamá, oiga la bruja. Vea, ahí se sentó". Y la oye uno que... y se ríe "cua cua cua" [SS: Onomatopeya] como una gente. Y entonces yo fui ahí y le eché unos tres ajos, y yo: “¡bueno, pues, cuidadito!”, y la regañé yo.

ENC: Y ¿qué fue lo que le dijo?, ¿Qué es eso de los ajos?

INF: ¡Carajo! le decía yo [SS: risas]

ENC: $\mathrm{Y}$ ¿se fue?

INF: No pasó más. Oyó" (Córdoba, 1975).

Este etnotexto relata la presencia de un ave nocturna que los campesinos reconocen como una bruja. En él se puede identificar la importancia de una cierta concepción del sonido: “¿usted nunca las ha oído?”; "uno las siente en el aire que va volando con un ruido". El reconocimiento de la bruja como ave nocturna se hace mediante el "ruido".

En el extracto presentado anteriormente podemos identificar una primera lista de ítems léxicos - "así", "uno las siente" y "con un ruido" - con los cuales la mujer entrevistada relata aquellas sensaciones y sonidos característicos de las brujas. Una segunda lista podría ser la siguiente: "siente uno la casa", "una noche", "oiga la bruja", "vea, ahí se sentó", expresiones con las cuales se describe la percepción de la presencia nocturna de la bruja cerca de la casa y las formas en que se le reconoce mediante el sonido. Finalmente, una tercera lista podría establecerse con la siguiente información: "y la oye uno que" y "y se ríe [...] como una gente", expresiones con las que se enfatiza que el sonido de la bruja no es solo un "ruido", sino de manera específica una risa: "y se ríe", que se asocia con "una gente".

Las brujas existen sonoramente, desde su vuelo hasta su risa. Los campesinos actúan en consecuencia acudiendo también al sonido para defenderse, como en el caso de la interlocutora, que grita "carajo", además de echar el ajo. La relación con las brujas se debe entender entonces a través de una red simbólica de los sonidos en el campo.

La relación con el espacio también es importante, como aparece mencionado en el mapa "bruja, hechicera" del ALEC: "las brujas en las casas". Allí se anota que para otros campesinos las brujas: "se paran en las cumbreras de las casas" (Antioquia, Tolima, Bolívar, Santander, Boyacá, Cesar), "salen por las noches" (Antioquia, Magdalena, Boyacá), se ubican en los árboles (Norte de Santander) o sobre los techos de las casas: "en forma de aves, se suben a los techos" (Tolima, Caldas), y "pasan volando y silbando sin ser vistas" (Boyacá) o "bailan como gualos" (Tolima, Santander). 
Debe entonces establecerse una relación entre el sonido, el acto de volar, la noche, el exterior de las casas y en particular sus techos. De acuerdo con la información identificada en los mapas y los etnotextos, las brujas prefieren ubicarse en lugares elevados (techos y árboles), el movimiento por el aire es constante y se hacen notar por medio de una serie de sonidos específicos como la risa o los silbidos. Esto nos permite entender que, según el esquema cultural campesino, las brujas no van a cualquier lugar, y tampoco lo hacen de cualquier manera. Existe entonces una serie de reglas tácitas, pero también explícitas, para interactuar con ellas. Si las brujas se manifiestan a través de una serie de sonidos específicos, es posible interactuar con ellas a través de otra serie de sonidos, como en este caso un grito o un regaño.

Estas expresiones muestran que el esquema cultural sobre la bruja voladora se entiende en relación con el conocimiento local de la naturaleza y la percepción y experiencia de los campesinos sobre el sonido de los animales, en particular nocturnos. Las distintas referencias del etnotexto y del mapa lingüístico "bruja, hechicera" sobre el vuelo nocturno de la bruja, dan a entender que la manera en que los campesinos le dan sentido a la experiencia de la bruja voladora es por medio de asociaciones con las aves del lugar y por su capacidad de distinguir su ruido, pues, según este etnotexto, la bruja incluso avisa de su presencia: “'bum bum bum' [SS: Onomatopeya], Atentito”.

En el caso de la naturaleza selvática chocoana, el etnotexto muestra que las brujas voladoras consiguen dominar aquella naturaleza nocturna que los campesinos solo conocen durante el día. Estas brujas hacen presencia en sus vidas cotidianas durante la noche, cuando el sentido del oído permite evitar que se acerquen a las casas y a los techos. Por ello, bajo estas circunstancias, toman sentido las acciones de la campesina para espantar a la bruja: "Y entonces yo fui ahí y le eché unos tres ajos, y yo: “¡bueno, pues, cuidadito!, y la regañé yo", y su confirmación de que: "No pasó más. Oyó”.

\section{Brujas dañinas: la concepción de los embrujos}

El análisis nos permitió identificar otra clasificación importante en relación con las brujas. Algunas solo se hacen notar por medio de sonidos específicos, mientras que otras realizan acciones que son consideradas dañinas. Sobre las brujas dañinas se encuentran referencias en los etnotextos del corpus lingüístico y en el mapa lingüístico "embrujar". Estas se relacionan con los conjuntos léxicos "hacer daños" (Sucre, Antioquia), "hacer maldad” (Antioquia, Córdoba, Chocó, Caquetá, Putumayo, Nariño, Cesar, Magdalena, Bolívar, Atlántico), "maliar" (Atlántico) o "hacer brujería (maleficio)" (Amazonas, Nariño, Cauca, Chocó, Valle del Cauca, Risaralda, Tolima, Caldas, Meta, Boyacá, Casanare, Arauca, Norte de Santander, Antioquia, Córdoba, Magdalena). Aun entre sus variaciones dialectales, se puede notar la importancia de atribuirle a las brujas la capacidad de "hacer daño", detrimento o perjuicio sobre las vidas de los campesinos en Colombia.

Carmen Campillo (Santafe de Antioquia, 1961) es una mujer campesina de al parecer avanzada edad. Se muestra simpática y traviesa mientras relata sus historias con humor. Habla de sí misma en tercera persona y al comenzar su relato, se ríe y dice: “¿Qué?, ¿más cuentos?”. Ella cuenta “sobre las brujas de Antioquia", según lo enuncia la entrevistadora, y acerca de las cuales realiza una clasificación de dos tipos: las "brujas volantonas"3 y las "brujas dañinas" (Campillo, 1961).

\footnotetext{
${ }^{3}$ Por “volantonas" podría tratarse de “volantón,-na” (Autoridades) o “volandero", adjetivo para un pájaro que está por salir a volar
} 
Hay unas brujas volantonas. Burleteras, según la expresión de ella. Esas vienen por la noche a las casas en donde tienen gallinas blancas, y se oye por la noche "jui jujui jujui jujui" [SS: Onomatopeya]. Esas no hacen daño. Se la pasan revoloteando y son burleteras, nomás. Las otras, las dañinas, vienen por la noche y están en los árboles en las fincas. Esas son las que hacen maleficios. Según Carmen Campillo pertenecen a familias reales. ¡Son principesas! según sus términos. Tienen unos tálamos muy bonitos, y se acuestan, y dejan las piernas allá para que la gente crea que están allá y se vienen a hacer daños. Después, por las mañanas se vuelven para sus camas como si nada hubiera pasado y en un momento recorren unas distancias enormes, se vienen desde Europa a hacer males aquí. Las oyen en los árboles por la noche y los embrujan.

Cuenta Carmen Campillo que a ella le embrujaron una noche que venía con una carga de leña que no encontró por dónde salir. Por todas partes eran alambrados, alambrados. Estaba lloviendo. Ella no podía salir de allá. Oía las carcajadas de la bruja y que le tiraban cosas. Por la mañana, cuando despertó, encontró que no había ningún alambrado por ninguna parte y era que la habían embrujado (Campillo, 1961).

En la cita anterior podemos identificar los siguientes ítems léxicos: "las dañinas", "vienen por la noche" y "están en los árboles en las fincas", con los cuales se logra identificar que para esta campesina las brujas "dañinas" llegan por las noches a las casas o a los árboles en las fincas. La expresión "esas son las que hacen maleficios" refuerza la apreciación de que las brujas dañinas pueden causar daños o "maleficios" por sus conocimientos de hechicería. Mientras que, en cuanto a la concepción de que "pertenecen a familias reales", esta "sirvienta de Antioquia" (como ella misma se presenta) hace notar que para ella las brujas tienen ciertos saberes y privilegios que le son desconocidos. El presentarse ella misma como "sirvienta" y a ellas como "principesas" nos permite identificar esa ausencia de conocimiento y hasta una suerte de admiración por tenerlo. Así lo muestra también la expresión: "tálamos muy bonitos" que "tienen" las brujas.

Los ítems léxicos de "y dejan las piernas allá," "para que la gente cree que están allá” y "y se vienen a hacer daños" nos devuelven a la conceptualización de las brujas voladoras. Según este etnotexto, las brujas que vuelan y son dañinas guardan el secreto de su condición: "las piernas escondidas". Mientras que los ítems "recorren unas distancias enormes", "se vienen desde Europa" y "a hacer males aquí" dan cuenta de las habilidades que tienen las brujas para atravesar distancias importantes.

Los genres de "vienen por la noche" y "y se vienen a hacer daños" comprenden los elementos léxicos de "vienen" o "se vienen", con referencia a que las brujas se desplazan hasta ciertos espacios o lugares rurales; y las condiciones de sus recorridos como que se transladan "por la noche" y "a hacer daños". Con estos genres queda nuevamente indicado el esquema cultural de las brujas voladoras, esta vez no para resaltar el sonido característico de las brujas que toman forma de ave, sino el desplazamiento entre espacios con la intención de hacer maleficios o causar daños.

Esta información permite crear una categorización del esquema cultural de las brujas voladoras de la siguiente manera: las brujas voladoras como conjunto general, y las brujas volantonas/burleteras,

(Real Academia Española); o al americanismo de "persona joven". En ambos casos se encuentra relación con las brujas voladoras. Sin embargo, la distinción de la hablante trata de la inocencia y las intenciones malignas de algunas brujas. 
así como las brujas dañinas, pueden entenderse como dos subconjuntos que hacen parte de la misma gran categoría. Las brujas burleteras se hacen notar por sus sonidos asociados a un cierto tipo de risas o de silbidos. Su intención es solo la de "burlarse" de las personas que se encuentran cerca de ellas, de ahí que la risa sea su rasgo característico. Por su parte, las brujas dañinas buscan ir un paso más allá; su intención es la de hacer daño, hacer maldad, afectando física o mentalmente la vida de los campesinos. Para lograr hacer daño, las brujas acuden entonces a los embrujos.

$\mathrm{Al}$ respecto de lo que significa para los campesinos de las distintas zonas del país "hacer daños", en el mapa "bruja, hechicera" podemos encontrar algunos elementos que dan cuenta de los distintos grados de afectación de los embrujos. La información encontrada permite listar los siguientes ítems léxicos sobre "las brujas en las casas", quienes pueden afectar de alguna manera los tejados, los coyabres, el chocolate, la vajilla, las matas de plátano, las cosas envolatadas, la ropa, el maltrato a los animales domésticos o las visitas de vecinos. Otros elementos son: "otras actuaciones de la bruja", "las brujas y la noche", "las brujas y el amor", "las brujas en los caminos" y "enfermedades que causan las brujas", en los cuales los actos malignos que comenten pueden llegar a ser incluso letales.

Sobre la bruja dañina y su relación con el espacio destacan los ítems léxicos "a ella le embrujaron una noche", "que venía con una carga de leña" y "que no encontró por dónde salir". Se hace referencia a la situación del embrujo, a las condiciones en las que ocurre y a la manera en que es experimentado. Los embrujos mencionados por los campesinos, cuando ocurren fuera de las casas suelen suceder a campo abierto o en lugares alejados. Dichos embrujos implican una transformación del espacio o por lo menos una sensación de transformación del entorno. El elemento más representativo de esa transformación es la sensación del encierro, de sentir que se está en un lugar del que no se puede salir o que no tiene salida. Pero también es posible perder el rumbo o el sentido de dirección. Así pues, a esta campesina le ocurrió "una noche" cuando realizaba la tarea cotidiana de llevar "una carga de leña", y experimentó un encierro del cual le fue imposible "salir".

Se encuentran otras menciones a la misma situación de embrujo en el mapa "bruja, hechicera". Se habla en términos de "las brujas en los caminos", como que "extravían a las personas, les hacen perder el camino" (Antioquia, Risaralda, Tolima, Bolívar, Magdalena, Cesar), "lo interrumpen” (Chocó), "lo vuelven un pantanero" (Antioquia) o "hacen perder a la gente en los montes" (Valle del Cauca). Por tales expresiones se puede comprender que en estos casos el embrujo se experimenta como un extravío, una confusión o una desorientación en espacios que, en circunstancias normales, son conocidos por los campesinos pues aparecen como lugares cotidianos. El espacio toma de nuevo una importancia capital: las brujas volantonas se quedan por fuera de la casa y no embrujan, mientras que las brujas dañinas pueden entrar en las casas y hasta modificar espacios abiertos diversos a través del acto del embrujo.

El esquema cultural de las brujas voladoras identificado en este caso permite no solo entender una clasificación y categorización de las brujas y la brujería en las regiones estudiadas por el ALEC, sino también responder a la pregunta de investigación: ¿¿cuáles son los esquemas culturales del campesinado colombiano asociados a la brujería, que les permiten nombrar y dar sentido a sus acciones y a su mundo? El esquema identificado en este caso muestra cómo el sonido organiza las interacciones con cierto tipo de animales voladores. También permite comprender cómo se organizan y se entienden los sonidos nocturnos y cómo se les da un sentido en relación con la figura de las brujas. Por otro lado, el esquema cultural devela también una concepción particular del espacio: los campesinos organizan sus recorridos 
en el campo teniendo en cuenta una serie de reglas asociadas a la brujería: evitan encontrarse en lugares alejados en los que es más propicio que un embrujo pueda ocurrir. De igual forma, el esquema da herramientas para entender cómo los campesinos han desarrollado una serie de estrategias para interactuar con las brujas y, por lo tanto, con su entorno natural. Dichas estrategias responden a la configuración del esquema cultural en términos del sonido, pero también de las formas de contrarrestar los embrujos.

\section{Conclusiones}

En la presente investigación sobre el ALEC se analizan y contrastan algunos de sus mapas lingüísticos con sus archivos sonoros relacionados con la brujería. Se abordan los archivos sonoros en tanto que etnotextos, y se hace uso de la herramienta analítica de los esquemas culturales a través de la identificación de aquellos patrones relacionales que conforman la estructura cognitiva sobre la cual las personas interpretan sus experiencias.

En términos metodológicos consideramos que la propuesta planteada en este caso es un aporte a los estudios de los etnotextos, pero también de los estudios en el ámbito de la lingüística cultural. Planteamos dos etapas en nuestro análisis: la primera, en la que se definen las bondades de los etnotextos como material de investigación interdisciplinaria, y la segunda, en la que se propone detectar esquemas culturales como procedimiento para hallar las estructuras conceptuales colectivas con las cuales las personas le otorgan sentido a su mundo. Con ellas se logra identificar un esquema cultural de la brujería que permite al campesinado colombiano nombrar y dar sentido a sus acciones y a su entorno.

Por otro lado, en este trabajo se plantean algunas diferencias interpretativas con relación a la propuesta original sobre los esquemas culturales (Malcolm y Sharifian, 2002). En lugar de optar por presentar convergencias léxicas y divergencias interpretativas entre diálogos interculturales, el interés de esta investigación se concentra en interpretar la lógica discursiva del campesinado que participó en la investigación del ALEC para develar aspectos de su vida cotidiana y de la configuración histórica colombiana. La pretensión no es comparar un mundo campesino frente a un mundo no campesino, sino dar cuenta a manera de esquemas culturales del patrimonio cultural colombiano.

Finalmente, este trabajo aporta al campo de los estudios del campesinado en Colombia una comprensión de los discursos campesinos sobre la interpretación de su propia vida en sus propios términos. Se espera que en trabajos posteriores se puedan analizar los léxicos de manera regional y comparativa, sobre los cuales se ha cumplido únicamente con presentar aquí su procedencia geográfica. Asimismo, se espera ofrecer interpretaciones sobre la vida campesina que revelen determinados modos subalternos de concebir la naturaleza, las relaciones entre clases sociales y ciertas concepciones sobre la salud y la enfermedad.

\section{Referencias}

Asatrian, G. (2009). Wörter Und Sachen-100: The Words and the Things. Iran e the Caucasus, 13(1), $209-211$. Bernal, J., e Hincapie, D. A. (2018). Lingüística de Corpus. Instituto Caro y Cuervo.

Bernales, M. (1980). Principios y orígenes del método 'Wörter und Sachen'. Documentos Lingüísticos y Literarios UACH, 5. http://www.humanidades.uach.cl/documentos_linguisticos/document.php?id=196

Bolaños, A. (2019). "Le dieron algo": la mecánica de los dones ocultos y la brujería en La Primavera, Vichada. En L. A. Suárez Guava (ed.), Cosas vivas: antropología de objetos, sustancias y potencias (pp. 289-304). Pontificia Universidad Javeriana. 
Bouvier, J.-C. (1978). Recherches sur les ethnotextes. Revue Régionale d'Ethnologie, 1-2, 251-253. https://doi. org $/ 10.3406 /$ mar.1978.1057

Bouvier, J.-C., y Ravier, X. (1976). Projet de recherche interdisciplinaire sur les ethnotextes du Sud de la France. En Revue Régionale d'Ethnologie, 1-2, 207-212.

Campillo, C. (1961, 13 de julio). "Relatos sobre cuentos tradicionales. En Instituto Caro y Cuervo CLICC. Corpus Lingüísticos del Instituto Caro y Cuervo (ALEC_C4_A5_ll). http://clicc.caroycuervo.gov.co/corpus/ALEC

Carvajal, M. (2011). La bruja y la embrujada: un caso de brujería en Bogotá. Maguaré, 25(2), 229-257.

Castaño, C. E., y Suárez, R. J. (1992). Las mujeres lechuza: historia, cuerpo y brujería en Boyacá. Instituto Colombiano de Cultura; Instituto Colombiano de Antropología e Historia.

Córdoba, A. (1975, 8 de febrero). Descripción sobre entierros y brujas hecha por una mujer en Coredó, Chocó. En Instituto Caro y Cuervo, ALEC digital. Atlas Lingüístico-Etnográfico de Colombia (ALEC_Cl5_Ch3_2). http:// alec.caroycuervo.gov.co/alec/

Dauzat, A. (1942) Le nouvel atlas linguistique de la France par régions: pour receuillir et étudier nos parlers ruraux. Impr. S. Pacteau.

Evans-Pritchard, E. E. (1976). Brujería, magia y oráculos entre los azande. Anagrama.

Favret-Saada, Jeanne (1980). Deadly Words. Witchcraft in the Bocage. Cambridge University Press.

Flórez, L. (1964). Principios y método del Atlas Lingüístico Etnográfico de Colombia (ALEC). Tesaurus. Boletín del Instituto Caro y Cuervo, XIX(2), 201-209. http://bibliotecadigital.caroycuervo.gov.co/339/1/ TH_19_002_001_l.pdf

Flórez, L. (1983). Atlas Lingüístico-Etnográfico de Colombia. Instituto Caro y Cuervo.

Ginzburg, C. (1991). Historia nocturna. Un desciframiento del aquelarre. Muchnik.

Gutiérrez de Pineda, V. (1985). Medicina tradicional de Colombia. Magia, religión y curanderismo (vol. 1-II). Universidad Nacional de Colombia.

Instituto Caro y Cuervo. (2017). CLICC. Corpus Lingüísticos del Instituto Caro y Cuervo. http://clicc.caroycuervo.gov. $\mathrm{co} /$ corpus/ALEC

Instituto Caro y Cuervo. (s. f.). ALEC digital. Atlas Lingüístico-Etnográfico de Colombia. http://alec.caroycuervo.gov. co/alec/

Joutard, P. (1981). A Regional Project: Ethnotexts. En Oral History, 9(1), 47-51.

Malcolm, I. G., y Sharifian, F. (2002). Aspects of Aboriginal English oral discourse: An application of cultural schema theory. Discourse Studies, 4(2), 169-181.

Michelet, J. (2004). La bruja. Una biografía de mil años fundamentada en las actas judiciales de la Inquisición. Akal.

Montes, J. J. (1976). Breve esbozo del ALEC: Desarrollo, enseñanzas, resultados probables. Revista de Letras, 18, $185-194$

Munévar, A., y Bernal, J. (en prensa). Brisas cruzadas: comparación de representaciones populares del aire y del viento en Colombia y en Francia". Chakiñan. Revista de Ciencias Sociales y Humanidades.

Nishida, H. (2005). Cultural Schema Theory. En W. B. Gudykunst (ed.), Theorizing about Intercultural Communication (pp. 401-413). Sage.

Pelen, J.-N. (1992). La recherche sur les ethnotextes. Notes sur un cheminement. IKER, 7, 709-726.

Pelen, J.-N. (2011). Les phonothèques de l'oral au carrefour de la recherche et de la culture. Bulletin de l'AFAS. Sonorités, 37. http://journals.openedition.org/afas/2813\%20;\%20DOI\%20:\%20https:/doi.org/10.4000/ afas. 2813

Ramos, A. L. (2017). Enfermedad postiza. La sospecha, lo subrepticio y lo aparente en narrativas e itinerarios de enfermedad. En D. M. Aponte, y D. M. Agudelo (eds.), Saberes y prácticas: miradas diversas en torno a procesos de salud y enfermedad (pp. 253-266). Universidad Externado de Colombia-Centro de Investigaciones sobre Dinámica Social.

Shahghasemi, E. (2017). Cultural Schema Theory. The International Encyclopedia of Intercultural Communication. John Wiley \& Sons, Inc.

Sharifian, F. (2017). Cultural Linguistics. Ethnolinguistic, 28, 33-61. https://doi.org/10.17951/et.2016.28.31

Suárez, L. A. (2009). Lluvia de flores, cosecha de huesos. Guacas, brujería e intercambio con los muertos en la Tragedia de Armero. Maguaré, 23, 371-416.

Taussig, M. (1993). Chamanismo, colonialismo y el hombre salvaje. Un estudio sobre el terror y la curación. Norma.

Uribe, C. A. (2003). Magia, brujería y violencia en Colombia. Revista de Estudios Sociales, 15, 59-73.

Van Dijk, T. A. (2000, 25 de octubre). Cognitive Discourse Analysis: An Introduction [ponencia]. Universidad Pompeu Fabra, Barcelona. http://www.discursos.org/unpublished\%20articles/cogn-dis-anal.htm 